\title{
Xenon preserves neutrophil and monocyte function in human whole blood
}

\author{
[Le xénon préserve la fonction des polynucléaires neutrophiles et des monocytes du \\ sang entier chez ['humain]
}

Lothar de Rossi MD, ${ }^{*}$ Karin Gott MD, ${ }^{*}$ Nicola Horn MD, ${ }^{*}$ Klaus Hecker MD, ${ }^{*}$ Gabriele Hutschenreuter MD,$\dagger$ Rolf Rossaint MD*

Purpose: Most volatile anesthetics are known to inhibit the oxidative and phagocytic function of neutrophils. In the present study, we investigated the effect of xenon on phagocytosis and respiratory burst activity of neutrophils and monocytes in human whole blood.

Methods: Heparinized whole blood from 22 healthy volunteers was incubated for $60 \mathrm{~min}$ in the presence of $65 \%$ xenon. Sixty-five percent nitrous oxide was used as a positive control to prove the reliability of our in vitro system. Phagocytosis of fluorescein isothiocyanate labelled, opsonized Escherichia coli (E. coli) by neutrophils and monocytes was measured using flow cytometry. After induction with either $\mathrm{N}$-formyl-methionyl-leucyl-phenylalanine (FMLP), phorbol-12-myristate-13-acetate or opsonized E. coli, respiratory burst activity was assessed by measuring the oxidation of dihydrorhodamine 123 to rhodamine 123 with a flow cytometer.

Results: Exposure of human whole blood to xenon increased the percentage of neutrophils showing phagocytosis ( $94 \pm 3 \%$ vs $92 \pm 4 \%$; $P<0.0 \mathrm{I})$, and the amount of ingested bacteria $(P<0.0 \mathrm{I})$. Respiratory burst activity in neutrophils and monocytes was not affected by xenon. Nitrous oxide significantly reduced the percentage of neutrophils showing respiratory burst after FMLP stimulation. Furthermore, E. coliinduced stimulation resulted in a decreased number of reacting neutrophils ( $84 \pm 15 \%$ vs $95 \pm 5 \% ; P<0.05)$ and monocytes (70 \pm $22 \%$ vs $83 \pm 11 \% ; P<0.05)$ as well as a reduced production of hydrogen peroxide in both cell lines compared to control.

Conclusion: In contrast to nitrous oxide, xenon preserves neutrophil and monocyte antibacterial capacity in vitro.
Objectif : La plupart des anesthésiques sont connus pour inhiber la fonction oxydative et phagocytaire des neutrophiles. Dans la présente étude, noua avons examiné l'effet du xénon sur la phagocytose et l'activité de pointe respiratoire des neutrophiles et des monocytes dans le sang entier humain

Méthode : Du sang entier hépariné de 22 donneurs en bonne santé a été incubé pendant 60 min en présence de xénon à $65 \%$. Du protoxyde d'azote à $65 \%$ a été utilisé comme témoin positif permettant de prouver la fiabilité de notre système in vitro. La phagocytose de l'isothiocyanate de fluorescéine marquée, de l'Escherichia coli (E. coli) opsonisé, par les neutrophiles et les monocytes a été mesurée à l'aide de la cytométrie de flux. Après l'induction avec, soit N-formyl-méthionylleucyl-phénylalanine (FMLP), soit phorbol-12-myristate-13-acétate ou E. coli opsonisé, l'activité de pointe respiratoire a été évaluée en mesurant l'oxydation de la dihydrorhodamine 123 en rhodamine 123 avec un cytomètre de flux.

Résultats : L'exposition du sang entier humain au xénon augmente le pourcentage de neutrophiles affichant une phagocytose ( $94 \pm 3 \%$ vs 92 $\pm 4 \% ; P<0,01)$ et la quantité de bactéries ingérées $(P<0,01)$. L'activité de pointe respiratoire dans les neutrophiles et les monocytes n'a pas été affectée par le xénon. Le protoxyde d'azote a significativement réduit le pourcentage de neutrophile montrant une pointe respiratoire après la stimulation avec la FMLP. De plus, la stimulation induite par l'E. coli a entraîné une baisse du nombre de neutrophiles ( $84 \pm 15 \%$ vs $95 \pm$ $5 \% ; P<0,05)$ et de monocytes (70 $\pm 22 \%$ vs $83 \pm 11 \%$ réactifs ; $P<0,05)$ ainsi qu'une production réduite de peroxyde d'hydrogène dans les deux souches cellulaires comparées aux cellules témoins.

Conclusion : Contrairement au protoxyde d'azote, le xénon préserve la capacité antibactérienne des neutrophiles et des monocytes in vitro.

From the Department of Anesthesiology, ${ }^{*}$ and the Institute of Transfusion Medicine, $†$ University Hospital, Rheinisch-Westfälische Technische Hochschule Aachen, Aachen, Germany. Address correspondence to: Dr. Lothar W. de Rossi, Department of Anesthesiology, University Hospital, Rheinisch-Westfälische Technische Hochschule, Pauwelsstr. 30, D-52074 Aachen, Germany. Phone: +49-241-8088179; Fax: +49-241-8888406; E-mail: L.derossi@gmx.de

Financial support: This study was supported by START, a research grant of the Rheinisch-Westfälische Technische Hochschule Aachen, Germany. Xenon was kindly donated by Messer GmbH, Krefeld, Germany.

Presentation: Parts of this manuscript were presented at the symposium "Current developments in anaesthesia", February $17^{\text {th }}$, Barcelona, Spain, and at the $11^{\text {th }}$ European Congress of Anesthesiology, Florence, Italy, 5-9 June 2001.

Accepted or publication April 29, 2002.

Revision accepted August 9, 2002. 


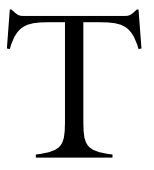

HE effects of xenon on the function of neutrophils and monocytes bactericidial function are still unknown. With the present study, we have investigated the effect of xenon in a clinically relevant concentration on phagocytosis and the respiratory burst activity in neutrophils and monocytes.

\section{Methods}

This study was approved by the local Institutional Review Board of our University hospital. After written informed consent, venous blood from healthy volunteers (12 male, 10 female) was drawn directly into blood collection tubes containing $15 \mathrm{IU} \cdot \mathrm{mL}^{-1}$ lithium heparin.

Blood samples were incubated for $60 \mathrm{~min}$ with either $65 \%$ xenon or $65 \%$ nitrous oxide, $21 \%$ oxygen and $5 \%$ carbon dioxide at $37^{\circ} \mathrm{C}$. Untreated blood samples used as controls were placed in an incubator (Heraeus BB 16, Germany). Xenon was delivered as a gas/oxygen/carbon dioxide mixture using a low-Pmass flow meter (Type F-201C-FA-22-V and E-7300AAA, HI-TEC Bronkhorst, The Netherlands). Nitrous oxide was delivered using a standard anesthetic machine (Cato, Dräger, Germany).

Gas concentrations within the box were continuously monitored using a multigas-analyzer (Datex Compact, Helsinki, Finland). Xenon gas concentrations were monitored with an Ecotec 500 Euro mass spectrometer (Leybold, Germany).

Phagocytosis activity was measured according to the recommendations of the manufactures, with minor modifications (Phagotest, Orpegen, Germany). This test measures the percentage of leukocytes showing phagocytosis and the phagocytic activity at the single cell level. ${ }^{3}$ In brief, after incubation, $100 \mu \mathrm{L}$ heparinized whole blood were placed on ice. After ten minutes, 20 $\mu \mathrm{L}$ opsonized and fluorescein isothiocyanate (FITC)labelled Escherichia coli (E. coli; $2 \times 10^{9} \mathrm{~mL}^{-1}$ ) were added for ten minutes at $37^{\circ} \mathrm{C}$. After incubation, samples were placed again on ice to stop further phagocytosis. Then, $100 \mu \mathrm{L}$ quenching solution $\left(4^{\circ} \mathrm{C}\right)$ was added and the samples were washed with phosphate buffered saline (PBS; $250 \mathrm{~g}$, five minutes, $4^{\circ} \mathrm{C}$ ). The cell pellet was lyzed and fixed (Lysing Solution ${ }^{\circledR}$, Becton-Dickinson, USA). The samples were washed again two times with PBS, and DNA staining was performed with $200 \mu \mathrm{L}$ propidium iodide $(1 \mathrm{mM})$.

A flow cytometric assay (Phagoburst, Orpegen, Germany) was used to assess the respiratory burst activity. $^{3}$ This assay allows quantification of the percentage of leukocytes showing respiratory burst activity as well as the amount of generated hydrogen oxygen. In brief, after incubation, $100 \mu \mathrm{L}$ heparinized whole blood were placed on ice for ten minutes. Three different stimuli were used: $\mathrm{N}$-formyl-methionyl-leucyl-phenylalanine (FMLP; $100 \mathrm{nM}$ ), phorbol-12-mystritate-13-acetate (PMA, $100 \mathrm{nM})$ and opsonized E. coli, $\left(20 \mu \mathrm{L}, 2 \times 10^{-}\right.$ $\left.{ }^{9} \cdot \mathrm{mL}^{-1}\right)$. After ten minutes of stimulation $\left(37^{\circ} \mathrm{C}\right), 20 \mu \mathrm{L}$ dihydrorhodamine 123 (DHR, $1 \mathrm{mM}$ ) was added and the samples were incubated for ten minutes at $37^{\circ} \mathrm{C}$. The stimulation was stopped by adding $2 \mathrm{~mL}$ Lysing Solution ${ }^{\circledR}$. After centrifugation $(250 \mathrm{~g}$, five minutes, $\left.4^{\circ} \mathrm{C}\right)$, cells were washed twice with PBS $(250 \mathrm{~g}$, five minutes, $4^{\circ} \mathrm{C}$ ) and the remaining cell pellet resuspended with PBS. DNA staining was performed with $200 \mu \mathrm{L}$ propidium iodide $(1 \mathrm{mM})$ for ten minutes on ice.

Flow cytometric analyses were performed on a FACSCalibur flow cytometer and analyzed using CellQuest 3.1 software (Becton-Dickinson, USA). Data acquisition and analyses were performed as previously described. ${ }^{1-3}$

In the phagocytosis assay, the percentage of FITCpositive neutrophils and monocytes reflects the percentage of cells containing FITC-labelled E. coli, whereas the mean FITC fluorescence intensity (MFI) correlates with the number of ingested bacteria per cell. In the respiratory burst assay, the percentage of rhodamine 123 positive phagocytes reflects the percentage of cells showing respiratory burst activity. The rhodamine 123 MFI is proportional to the amount of hydrogen peroxide generated by the individual phagocyte.

\section{Statistical analysis}

All data are presented as mean values and standard deviation. Differences between drug-exposed and untreated control samples assessed in parallel were evaluated using paired t test. $P<0.05$ was considered significant.

\section{Results}

Xenon increased the percentage of neutrophils showing phagocytosis and the number of ingested bacteria per neutrophil (Table I). Nitrous oxide did not influence phagocytosis activity (Table II).

After stimulation with FMLP, PMA or opsonized E. coli, the percentage of either neutrophils or monocytes showing respiratory burst activity as well as the amount of generated hydrogen peroxide was not affected by xenon (Figure 1). Nitrous oxide significantly reduced the percentage of neutrophils with respiratory burst activity after stimulation with FMLP (Figure 2). Furthermore, nitrous oxide also reduced the percentage of neutrophils and monocytes showing respiratory burst activity and the total oxidative response to opsonized E. coli. 
TABLE I Effect of xenon on phagocytosis activity in neutrophils and monocytes

\begin{tabular}{lllll}
\hline & \multicolumn{2}{c}{ Neutrophils } & \multicolumn{2}{c}{ Monocytes } \\
& \% positive cells & MFI positive cells & MFI \\
\hline Xenon & $94(3)^{*}$ & $1094(195)^{*}$ & $75(21)$ & $699(206)$ \\
Control & $92(4)$ & $948(143)$ & $79(7)$ & $637(143)$ \\
\hline
\end{tabular}

MFI $=$ mean fluorescence activity. Results are mean $(\mathrm{SD})$ of ten independent experiments. ${ }^{*} P<0.01$ compared with control values.

TABLE II Effect of nitrous oxide on phagocytosis activity in neutrophils and monocytes

\begin{tabular}{lllll}
\hline & \multicolumn{2}{c}{ Neutrophils } & \multicolumn{2}{c}{ Monocytes } \\
& \% positive cells & MFI positive cells & MFI \\
\hline Nitrous oxide & $93(5)$ & $1189(303)$ & $76(8)$ & $780(135)$ \\
Control & $94(3)$ & $1266(341)$ & $78(6)$ & $863(184)$ \\
\hline
\end{tabular}

$\mathrm{MFI}=$ mean fluorescence activity. Results are mean $(\mathrm{SD})$ of 11 independent experiments.
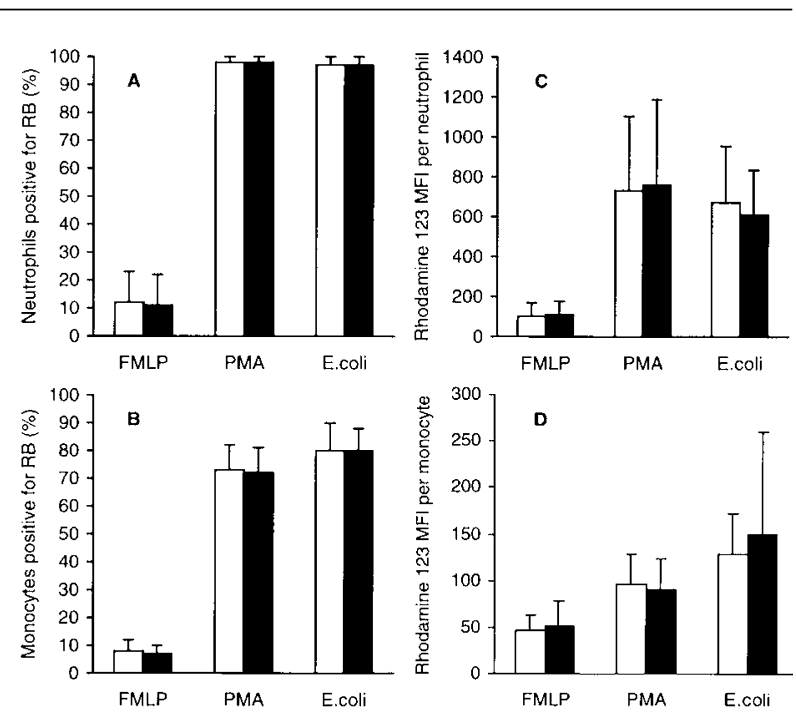

FIGURE 1 Effect of xenon ( $)$ on agonist-induced respiratory burst $(\mathrm{RB})$ activity in neutrophils and monocytes in comparison with with untreated control ( $\square$ ). Whole blood was stimulated with either N-formyl-methionyl- leucyl-phenylalanine (FMLP; 100 $\mathrm{nM}$ ), phorbol-12-mystritate-13-acetate (PMA; $100 \mathrm{nM}$ ), or opsonized Escherichia coli (E. coli; $\left.2 \times 10^{9} \cdot \mathrm{mL}^{-1}\right)$. Data are presented as percentage of neutrophils/monocytes showing respiratory burst activity $(\mathrm{A}, \mathrm{B})$, and the rhodamine 123 mean fluorescence intensity (MFI) per single cell (C,D). The rhodamine 123 MFI represents the generated amount of hydrogen peroxide per neurophil/monocyte (mean \pm SD of 11 independent experiments).

\section{Discussion}

In the current study, we investigated the effect of xenon on two major components of the phagocytic process of neutrophils and monocytes in human whole blood. In a clinically used concentration, xenon had no obvious
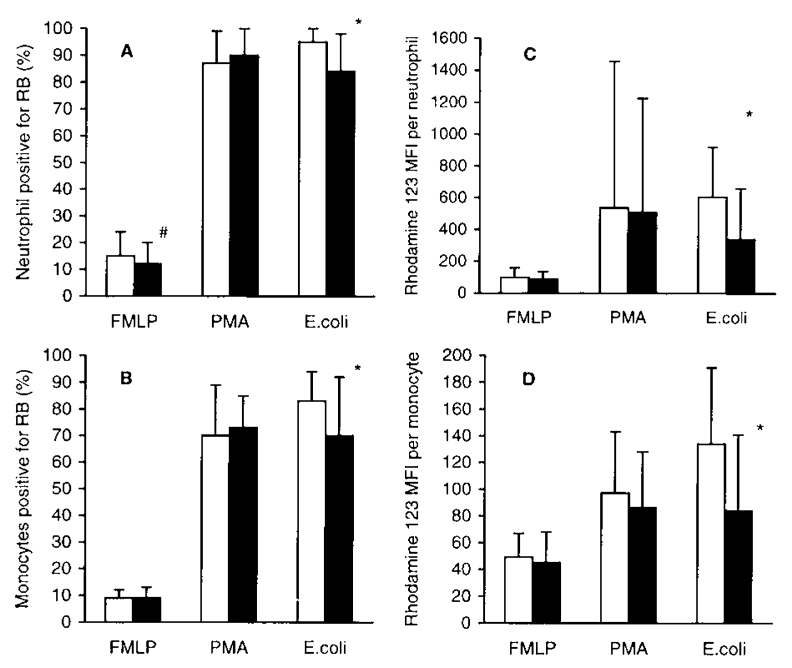

FIGURE 2 Effect of nitrous oxide ( $\mathbf{\square})$ on agonist-induced respiratory burst $(\mathrm{RB})$ activity in neutrophils and monocytes in comparison with untreated control $(\square)$. Whole blood was stimulated with either N-formyl- methionyl-leucyl-phenylalanine (FMLP; 100 $\mathrm{nM}$ ), phorbol-12-mystritate-13-acetate (PMA; $100 \mathrm{nM}$ ), or opsonized Escherichia coli (E. coli; $\left.2 \times 10^{9} \cdot \mathrm{mL}^{-1}\right)$. Data are presented as percentage of neutrophils/monocytes showing respiratory burst activity $(\mathrm{A}, \mathrm{B})$, and the rhodamine 123 mean fluorescence intensity (MFI) per single cell (C,D). The rhodamine $123 \mathrm{MFI}$ represents the generated amount of hydrogen peroxide per neutrophil/monocyte (mean \pm SD of 11 independent experiments). ${ }^{*} P<0.05 ; \# P<0.01$ for control $v s$ nitrous oxide exposed.

effect on the respiratory burst activity of neutrophils or monocytes. However, xenon increased the percentage of neutrophils showing phagocytosis activity, and the amount of ingested E. coli per neutrophil. 
Intracellular elimination of invading bacteria by neutrophils and monocytes depends mainly on the generation of reactive oxygen species during the phagocytosis-associated respiratory burst. ${ }^{4}$ To allow comparison with previous studies, ${ }^{1,2}$ respiratory burst activity was induced with FMLP as a physiological agonist. PMA, a direct activator of protein kinase $\mathrm{C}$ (PKC), was used to identify possible effects on the intracellular signaling pathway. Since phagocytosis depends upon direct contact of neutrophils and monocytes with bacteria, ${ }^{5}$ that have been opsonized by immune globulines and/or the complement component C3b, we also used opsonized E. coli as physiological stimulus of phagocytosis-related generation of respiratory burst.

After exposure to xenon neither neutrophils nor monocytes showed changes in their respiratory burst activity. In contrast, nitrous oxide reduced the amount of hydrogen peroxide produced per neutrophil after stimulation with FMLP, which is inconsistent with previous results. ${ }^{2}$ However, we could not detect a reduction in the percentage of neutrophils showing respiratory burst activity after exposure to nitrous oxide. This discrepancy might be explained by methodological differences.

An interesting new finding of our study was the inhibition of the E. coli-induced respiratory burst activity of neutrophil and monocytes by nitrous oxide. The signaling pathways activated by binding of IgGopsonized bacteria to FcRs on the surface of neutrophils and monocytes are incompletely established. Engagement of the IgG-ligand leads to FcRs-receptor aggregation and activation of cytosolic tyrosine kinases, most notably Syk. ${ }^{5,6}$ Events downstream of Syk activation are less well known, but evidence suggests that cytoskeletal alterations and phagocytosis as well as respiratory burst activity are mediated by the GTPases Cdc42 and Rac. ${ }^{5,7}$ In the present study nitrous oxide did not affect FcRs-mediated phagocytosis and PMAinduced respiratory burst. Therefore, we suggest that nitrous oxide might interfere with the intracellular signaling pathway downstream of the GTPases Cdc42 and Rac, and upstream of PKC.

Xenon caused a small increase in the percentage of neutrophils showing phagocytosis and in the amount of ingested bacteria per cell. Enflurane has been shown to decrease phagocytosis, ${ }^{8}$ whereas halothane, ${ }^{9}$ isoflurane, and nitrous oxide ${ }^{8}$ had no effect. Neutrophil and monocyte phagocytosis activity following exposure to nitrous oxide was also not affected in our study. However, we suggest that the small increase in the phagocytic activity of neutrophils is clinically not important.
In conclusion, the results of our study show that xenon preserves neutrophil and monocyte antibacterial capacity in vitro.

\section{References}

1 Fröhlich D, Rothe G, Schwall B, et al. Effects of volatile anaesthetics on human neutrophil oxidative response to the bacterial peptide FMLP. Br J Anaesth 1997; 78:

718-23.

2 Fröhlich D, Rothe G, Wittmann S, et al. Nitrous oxide impairs the neutrophil oxidative response.

Anesthesiology 1998; 88: 1281-90.

3 Heine J, Jaeger K, Osthaus A, et al. Anaesthesia with propofol decreases FMLP-induced neutrophil respiratory burst but not phagocytosis compared with isoflurane. Br J Anaesth 2000; 85: 424-30.

4 Burg ND, Pillinger $M H$. The neutrophil: function and regulation in innate and humoral immunity. Clin Immunol 2001; 99: 7-17.

5 Greenberg $S$. Modular components of phagocytosis. J Leukoc Biol 1999; 66: 712-7.

6 Salmon JE, Brogle NL, Edberg JC, Kimberly RP. Fc receptor III induces actin polymerization in human neutrophils and primes phagocytosis mediated by Fc receptor II. J Immunol 1991; 146: 997-1004.

7 Caron E, Hall A. Identification of two distinct mechanisms of phagocytosis controlled by different Rho GTPases. Science 1998; 282: 1717-21.

8 Welch WD. Effect of enflurane, isoflurane, and nitrous oxide on the microbicidal activity of human polymorphonuclear leukocytes. Anesthesiology 1984; 61: 188-92.

9 Nunn JF, Sturrock JE, Jones AJ, et al. Halothane does not inhibit human neutrophil function in vitro. Br J Anaesth 1979; 51: 1101-8. 